\title{
Association Study between Idiopathic Scoliosis and Polymorphic Variants of VDR, IGF-1, and AMPD1 Genes
}

\author{
Svetla Nikolova, ${ }^{1}$ Vasil Yablanski, ${ }^{2}$ Evgeni Vlaev, ${ }^{2}$ Luben Stokov, ${ }^{3}$ \\ Alexey Slavkov Savov, ${ }^{1}$ and Ivo Marinov Kremensky ${ }^{4}$ \\ ${ }^{1}$ National Genetic Laboratory, Department of Obstetrics and Gynecology, Faculty of Medicine, Medical University-Sofia, \\ 2 Zdrave Street, 14th Floor, 1431 Sofia, Bulgaria \\ ${ }^{2}$ Tokuda Hospital Sofia, Orthopedic and Traumatology Clinic, 51B Nikola Vaptsarov Boulevard, 1407 Sofia, Bulgaria \\ ${ }^{3}$ University Orthopedic Hospital "Prof. Boycho Boychev", Medical University-Sofia, 56 Nikola Petkov Boulevard, 1614 Sofia, Bulgaria \\ ${ }^{4}$ Molecular Medicine Center, Medical University-Sofia, 2 Zdrave Street, 14th Floor, 1431 Sofia, Bulgaria
}

Correspondence should be addressed to Svetla Nikolova; snikolova83@abv.bg

Received 13 July 2015; Accepted 18 August 2015

Academic Editor: Jerzy Kulski

Copyright (C) 2015 Svetla Nikolova et al. This is an open access article distributed under the Creative Commons Attribution License, which permits unrestricted use, distribution, and reproduction in any medium, provided the original work is properly cited.

Idiopathic scoliosis (IS) is a complex genetic disorder of the musculoskeletal system, characterized by three-dimensional rotation of the spine with unknown etiology. For the aims of the current study we selected 3 single nucleotide polymorphisms with a low incidence of the polymorphic allele in Bulgarian population, AMPD1 (rs17602729), VDR (rs2228670), and IGF-1 (rs5742612), trying to investigate the association between these genetic polymorphisms and susceptibility to and progression of IS. The polymorphic regions of the genes were amplified by polymerase chain reaction (PCR). The PCR products were cleaved with the appropriate restriction enzymes. The statistical analysis was performed by Pearson's chi-squared test. A value of $p<0.05$ was considered to be statistically significant. In conclusion, this case-control study revealed no statistically significant association between the VDR, IGF-1, and AMPD1 polymorphisms and the susceptibility to IS or curve severity in Bulgarian patients. Replication case-control studies will be needed to examine the association between these candidate-genes and IS in different populations. The identification of molecular markers for IS could be useful for early detection and prognosis of the risk for a rapid progression of the curve. That would permit early stage treatment of the patient with the least invasive procedures.

\section{Introduction}

The failure of genome-wide association studies to account for most heritability of complex diseases has invoked some considerable discussion on the reasons for "missing heritability" [1]. Factors thought to contribute to this missing heritability are genetic interactions [2] and rare variants [3]. Rare disease variants are thought to exist as recently derived highly penetrant alleles that have a low population frequency but account for high disease susceptibility [4]. The contribution of rare variants to complex diseases has been the topic of much consideration and early investigations have suggested promising results [5].

Idiopathic scoliosis (IS) is a complex genetic disorder of the musculoskeletal system, characterized by threedimensional rotation of the spine with unknown etiology.
It is known that vitamin $\mathrm{D}$ receptor (VDR) plays an important role in the regulation of bone mass development. Adolescence is a critical time for the acquisition of bone mass; around $40 \%$ of skeletal mass is acquired during pubertal maturation [6]. Morrison et al. reported that a VDR BsmI polymorphism is responsible for peak bone mass formation [7]. Suh et al. conducted a study between adolescent idiopathic scoliosis (AIS) and the VDR FokI (rs2228670), BsmI (rs1544410), and Cdx2 (rs11568820) gene polymorphisms and found association between the VDR BsmI polymorphism and bone mineral density at the lumbar spine in girls with AIS [8]. Yilmaz et al. found no correlation between the VDR BsmI polymorphism and curve progression [9].

FokI restriction polymorphism could be considered as an independent marker in the VDR gene since there is no linkage disequilibrium (LD) with any of the other VDR 
polymorphisms [10]. Therefore, LD with another polymorphism is not a likely explanation for the associations observed with this polymorphism, and so functional studies should be focussed on the polymorphism itself. Two protein variants can exist corresponding to the two polymorphic alleles: a long version of the VDR protein (the T-allele or the "f" allele) and a protein shortened by three amino acids (the C-allele or the " $F$ " allele) [11]. In a study by Arai et al., evidence for the functionality of the FokI polymorphism was obtained. Results from transcriptional activation studies in transfected HeLa cells suggested the short 424-amino-acid VDR protein variant (corresponding with the C-allele or "big F" allele) to be more active than the long 427-amino-acid variant, with a 1.7-fold difference between the two variants [12]. Jurutka et al. demonstrated the 424-amino-acid VDR variant to interact more efficiently with the transcription factor TFIIB. The authors concluded the 424-amino-acid short VDR variant to represent a more transcriptionally potent VDR protein [13].

The importance of insulin-like growth factor-1 (IGF-1) in skeletal growth makes it a good candidate-gene which would play a role in the documented association of rapid growth with curve progression in IS. Yeung et al. found that the IGF-1 promoter polymorphism rs5742612 affects the curve severity of AIS and may be a disease modifying gene [14]. The irregular expression of growth hormone and insulin-like growth factor-1 (IGF-1) may disturb hormone metabolism, result in a gross asymmetry, and promote the progress of adolescent idiopathic scoliosis [15]. Takahashi et al. concluded that IGF-1 gene polymorphism rs5742612 is not associated with either AIS predisposition or curve severity in the Japanese [16]. Moon et al. revealed that the IGF-1 rs5742612 polymorphism is associated with both susceptibility to and curve severity in AIS in Korean patients [17].

The adenosine monophosphate deaminase 1 (AMPD) is expressed in the skeletal muscles, where it plays a role in the production of energy. The nonsense mutation c.34C $>\mathrm{T}$ ( C to $\mathrm{T}$ transition in nucleotide 34, p.Gln12X, rs17602729) in exon 2 of the AMPD1 gene converts glutamine codon (CAA) into the premature stop codon (TAA), which results in the early interruption of protein synthesis and appears to be the main cause of AMPD deficiency [18]. Studies have shown that part of the population who express the mutant AMPD1 Tallele ( $2 \%$ of the Caucasian population are homozygous) are vulnerable to muscle weakness, muscular cramps, pain, and premature fatigue during exercises [19].

The effects of scoliosis include poor posture, shoulder humping, muscle weakness, and pain. The AMPD1 (rs17602729) polymorphism is not investigated in patients with IS.

For the aims of the current study we selected 3 single nucleotide polymorphisms with a low incidence of polymorphic allele in Bulgarian population, AMPD1 (rs17602729, C/T; C34T), VDR (rs2228670, T/C; FokI), and IGF-1 (rs5742612 $\mathrm{C} / \mathrm{T}$ ), trying to investigate the association between these genetic polymorphisms and susceptibility to and progression of IS.

\section{Materials and Methods}

In this study, Bulgarian patients with IS $(n=105)$ and healthy unrelated gender-matched controls $(n=210)$ were included. All participants in the study were informed about its purpose and were included only after the subjects/families signed their informed consent. Peripheral blood samples were obtained from patients and control subjects. The study protocol was approved by the Ethics Committee of the Medical UniversitySofia (number 2987/2012).

2.1. Patients. Patients with IS were recruited with the help of orthopaedic surgeons from Tokuda Hospital Sofia and University Orthopedic Hospital "Prof. Boycho Boychev." The IS diagnosis was confirmed clinically and radiologically. Scoliosis as a phenotypic characteristic like Marfan's syndrome was excluded. The curves were measured by the Cobb method. The mean value of Cobb angles was $54.5 \pm 22.6$. The mean age at the beginning of the disease was $11.2 \pm 3.1$ years. In this study, male $(n=19)$ and female $(n=86)$ patients were included.

2.2. Controls. The control group including healthy subjects without clinical signs of IS was recruited from a pool of unrelated gender-matched volunteers from other units and clinics of Tokuda Hospital Sofia, National Genetic Laboratory, hospital staff members, and students. The controls were selected among adult patients with skeletal maturity with negative family history of IS. Radiological examination was not performed in the control group.

2.3. Genotyping. Genomic DNA was extracted from the peripheral blood leucocytes using magnetic bead technology (chemagic DNA Blood Kit special, Chemagen) on automated high throughput nucleic acid isolation platform (chemagic Magnetic Separation Module I, Chemagen).

The polymorphic regions of the genes were amplified by polymerase chain reaction (PCR). The primer sets are listed in Table 1.

The PCR was carried out in a reaction mix of $20 \mu \mathrm{L}$ containing 100-ng DNA and 10x Prime Taq buffer (Genet Bio), $10 \mathrm{mM}$ dNTPs Mixture (Genet Bio), 20 pmol Forward and Reverse primers (Alpha DNA), and 0.1 U Prime Taq DNA Polymerase (Genet Bio). PCR amplification was performed in an AB 2720 Thermocycler (Life Technologies) with an initial denaturation at $94^{\circ} \mathrm{C}$ for five minutes and a final extension of seven minutes at $72^{\circ} \mathrm{C}$. The following thermal cycle was repeated 30 times: denaturation at $94^{\circ} \mathrm{C}$ for 30 seconds, annealing for 30 seconds at temperature presented in Table 2 , and extension at $72^{\circ} \mathrm{C}$ for 30 seconds.

The PCR products were cleaved with the appropriate restriction enzymes (New England Biolabs), according to the manufacturer's instructions, and the restriction fragments were separated on agarose $3 \%$ gel in VG-SYS Horizontal Electrophoresis System (Biochrom). The restriction enzymes and the lengths of the fragments representing the genotypes are presented in Table 2 . 
TABLE 1: PCR primers.

\begin{tabular}{ll}
\hline Gene, polymorphism & Primers \\
\hline $\operatorname{VDR}(\mathrm{rs} 2228670)$ & Forward: $5^{\prime}$-AGCTGGCCCTGGCACTGACTCTGCTCT-3 \\
& Reverse: $5^{\prime}$-ATGGAAACACCTTGCTTCTTCTCCCTC-3' \\
IGF-1 (rs5742612) & Forward: $5^{\prime}$-CACACACACAGGTTTGAGTTATATG-3 \\
& Reverse: $5^{\prime}$-GGTAAAGTAGATTGGAAGACAGC-3' \\
AMPD1 (rs17602729) & Forward: $5^{\prime}$-CTCTGACAAATGGCAGCAAA-3' \\
& Reverse: $5^{\prime}$-TGTCTACCCCAAAGCAGTGA-3' \\
\hline
\end{tabular}

TABLE 2: PCR-RFLP protocol.

\begin{tabular}{|c|c|c|c|c|}
\hline Gene, polymorphism & Annealing temperature, ${ }^{\circ} \mathrm{C}$ & $\begin{array}{l}\text { PCR product } \\
\text { size, bp }\end{array}$ & Restriction enzyme & $\begin{array}{l}\text { Restriction } \\
\text { fragments, bp }\end{array}$ \\
\hline$V D R(\mathrm{rs} 2228670)$ & 59 & 265 & FokI & $\begin{array}{c}\text { FF: } 265 \\
\text { Ff: } 265+196+69 \\
\text { ff: } 196+69\end{array}$ \\
\hline$I G F-1(\mathrm{rs} 5742612)$ & 59 & 330 & BslI & $\begin{array}{c}\text { TT: } 330 \\
\text { CT: } 330+277+53 \\
\text { CC: } 277+53\end{array}$ \\
\hline AMPD1 (rs17602729) & 58 & 136 & MaeII & $\begin{array}{c}\text { CC: } 97+39 \\
\text { CT: } 136+97+39 \\
\text { TT: } 136\end{array}$ \\
\hline
\end{tabular}

PCR indicates polymerase chain reaction; RFLP: restriction fragment length polymorphism; bp: base pair; VDR: vitamin D receptor; IGF-1: insulin-like growth factor-1; AMPD1: adenosine monophosphate deaminase 1.

2.4. Statistical Analysis. The statistical analysis was performed by Pearson's chi-squared test to make genotype and allele comparisons between cases and controls and test for Hardy-Weinberg equilibrium. A value of $p<0.05$ was considered to be statistically significant for comparison between data sets. Odds ratios (OR) were calculated with 95\% confidence interval (95\% CI). Statistical analysis was conducted with the SPSS 19.0 software package for Windows.

\section{Results and Discussion}

Predisposition for IS, like other examples of complex traits, does not have a specific assigned risk of heritability, but inheritance is based on multiple factors, potentially both genetic and environmental [20]. This study examined the association between IS and AMPD1 (rs17602729, C/T; C34T), $\operatorname{VDR}$ (rs2228670, T/C; FokI, F/f), and IGF-1 (rs5742612 C/T). Genotypes were in Hardy-Weinberg equilibrium.

The overall frequencies of the FF and the ff genotype of the $V D R$ (rs2228670) in the patients with IS were comparable with the controls ( $\mathrm{FF}$ versus $\mathrm{Ff}+\mathrm{ff}, p=0.75$ ). In conclusion, a specific genotype/allele was not associated with a higher risk of scoliosis (FF versus Ff + ff; OR: 1.08; CI: 0.68-1.73; F versus f, $p=0.89$; OR: 1.02; CI: 0.7-1.49). The genotype and allele frequencies of IGF-1 (rs5742612) were also comparable between cases and controls (TT versus CC + CT, $p=0.71$; OR: 1.15 ; 95\% CI: $0.54-2.45$; T versus C, $p=0.57$; OR: 1.22 ; 95\% CI: 0.61-2.45). The genotype and allele frequencies of AMPD1 (rs17602729) were also comparable between cases and controls (CC versus CT + TT, $p=0.6$; OR: 0.87; 95\% CI: $0.52-1.45$; $C$ versus T, $p=0.4$; OR: 0.83 ; 95\% CI: $0.53-1.29$ ).
On the basis of these results the genetic variants of $V D R$, $I G F-1$, and $A M P D 1$ alone could not be considered as predisposing factors for IS in Bulgarian population. Previously, Suh et al. found an association between the VDR BsmI polymorphism and bone mineral density in AIS patients but they found no correlation between FokI polymorphism and AIS [8]. Yilmaz et al. reported no statistically significant association between the VDR BsmI polymorphism and AIS in Turkish patients [9]. The genetic association between IGF1 promoter polymorphism rs5742612 and AIS predisposition was found among Korean [17] but not in Japanese population group [16]. The different results for $I G F-1$ could be explained with different genotype and allele frequencies in different population and ethnic groups. Additional case-control studies will be necessary to examine the potential association between other VDR polymorphisms and IS in different population groups. There is no data for previous association studies between C34T AMPD1 gene polymorphism and IS. Replication studies will be necessary to confirm our results.

The genotype and allele frequencies of the case and the control group are summarised in Table 3.

In the subgroup of surgical cases $(n=84)$ where Cobb angle $>40^{\circ}$ the genotype and allele frequencies of the VDR (rs2228670) polymorphism were comparable between cases and controls (FF versus Ff $+\mathrm{ff}, p=0.82$; OR: 0.94; $95 \%$ CI: $0.57-1.57$; F versus f, $p=0.86$; OR: 0.96 ; 95\% CI: $0.65-$ 1.44). The genotype and allele frequencies of the AMPD1 (rs17602729) polymorphism were also comparable between cases and controls (CC versus TT $+\mathrm{CT}, p=0.33$; OR: 0.76 ; 95\% CI: 0.44-1.32; C versus T, $p=0.17$; OR: 0.72 ; $95 \% \mathrm{CI}$ : $0.45-1.15$ ). In this subgroup, IGF-1 (rs5742612) CC genotype 
TABLE 3: Genotype and allele frequency distributions in patients $(n=105)$ with idiopathic scoliosis (IS) and healthy controls $(n=$ 210).

\begin{tabular}{lccc}
\hline $\begin{array}{l}\text { Gene, } \\
\text { polymorphism }\end{array}$ & $\begin{array}{c}\text { Genotype, } \\
\text { allele }\end{array}$ & $\begin{array}{c}\text { Cases } \\
n, \%\end{array}$ & $\begin{array}{c}\text { Controls } \\
n, \%\end{array}$ \\
\hline & FF & $56(53.3)$ & $108(51.4)$ \\
VDR & Ff & $43(41.0)$ & $92(43.8)$ \\
(rs2228670) & ff & $6(5.7)$ & $10(4.8)$ \\
& F & $155(73.8)$ & $308(73.3)$ \\
& f & $55(26.2)$ & $112(26.7)$ \\
\hline IGF-1 & TT & $94(89.5)$ & $185(88.1)$ \\
(rs5742612) & CT & $10(9.5)$ & $21(10.0)$ \\
& CC & $1(1.0)$ & $4(1.9)$ \\
& T & $198(94.3)$ & $391(93.1)$ \\
AMPD1 & C & $12(5.7)$ & $29(6.9)$ \\
\hline (rs17602729) & CC & $73(69.5)$ & $152(72.4)$ \\
& CT & $27(25.7)$ & $53(25.2)$ \\
& TT & $5(4.8)$ & $5(2.4)$ \\
& C & $173(82.4)$ & $357(85.0)$ \\
\hline
\end{tabular}

All $p$ values were not significant. VDR indicates vitamin D receptor; IGF-1: insulin-like growth factor-1; AMPDI: adenosine monophosphate deaminase 1.

was not observed (TT versus CC + CT, $p=1$; OR: $1 ; 95 \%$ CI: $0.46-2.18$; $T$ versus $C, p=0.67$; OR: 1.17 ; $95 \%$ CI: $0.56-2.46$ ).

In conclusion, these polymorphisms could not be considered as modifying factors of IS associated with a rapid progression of the deformity in Bulgarian population. First, Yeung et al. found that the IGF-1 promoter polymorphism rs5742612 affects the curve severity of AIS and may be a disease modifying gene in Chinese population [14]. Takahashi et al. concluded that IGF-1 gene polymorphism rs5742612 is not associated with either AIS predisposition or curve severity in Japanese population [16]. Moon et al. revealed that the IGF-1 rs5742612 polymorphism is associated with both susceptibility to and curve severity in AIS in Korean patients [17]. On the basis of these results IGF-1 remains a candidategene of IS and replication studies are necessary to investigate the contribution of the IGF-1 polymorphic variants in the etiopathogenesis of IS in different population groups.

Adolescent idiopathic scoliosis (AIS) is the most common spinal deformity [21] and the most frequently studied idiopathic scoliosis $[8,9,14,16,17]$. In the subgroup of the adolescents $(n=78)$ the genotype and allele frequencies of the VDR (rs2228670) polymorphism were comparable between cases and controls (FF versus $\mathrm{Ff}+\mathrm{ff}, p=0.72$; OR: 1.1; CI: $0.65-1.86$; $F$ versus $f, p=0.92$; OR: 1.02 ; $95 \%$ CI: $0.67-1.55)$. The genotype and allele frequencies of the IGF-1 (rs5742612) polymorphism were comparable between cases and controls (TT versus CC $+\mathrm{CT}, p=0.84$; OR: 0.92 ; 95\% CI: $0.42-2.01$; $C$ versus T, $p=1$; OR: 0.98 ; $95 \%$ CI: $0.48-2.01$ ). The genotype and allele frequencies of the AMPD1 (rs17602729) polymorphism were also comparable between cases and controls (CC versus TT $+\mathrm{CT}, p=0.6$; OR: 0.86 ; CI: $0.49-1.51$; C versus T, $p=0.5$; OR: 0.84 ; 95\% CI: $0.51-1.38$ ). These results showed the polymorphisms are not associated with the susceptibility to AIS and confirmed the negative association between the FokI polymorphism and AIS [8] and IGF-1 (rs5742612) and AIS [16].

In the subgroup of the familial cases $(n=28)$ the genotype and allele frequencies of the $V D R$ (rs2228670) were comparable between cases and controls ( $\mathrm{FF}$ versus $\mathrm{Ff}+\mathrm{ff}$, $p=0.36$; OR: 1.46 ; $95 \%$ CI: $0.65-3.27$; F versus $\mathrm{f}, p=0.58$; OR: 1.2; CI: 0.62-2.32). The genotype and allele frequencies of the IGF-1 (rs5742612) were comparable between cases and controls (TT versus CC + CT, $p=0.55$; OR: 1.76 ; 95\% CI: $0.39-7.85$; $T$ versus C, $p=0.79$; OR: 1.31 ; 95\% CI: 0.39-4.45). The genotype and allele frequencies of AMPD1 (rs17602729) were also comparable between cases and controls (CC versus TT + CT, $p=0.13$; OR: 2.29 ; 95\% CI: $0.76-6.88$; C versus T, $p=0.11$; OR: 2.29; CI: 0.8-6.57). In conclusion, the genotypes and alleles of these polymorphisms could not be associated with the familial history of IS.

Scoliosis is more common in females than males. In the subgroup of female patients $(n=86)$ no statistically significant associations between the VDR, IGF-1, and AMPD1 polymorphisms and the clinical phenotype were observed (AMPD1 (rs17602729), CC versus TT $+\mathrm{CT}, p=0.92$, and $\mathrm{C}$ versus T, $p=0.86 ; V D R$ (rs2228670), $\mathrm{FF}$ versus $\mathrm{Ff}+\mathrm{ff}$, $p=0.48$, and $\mathrm{F}$ versus f, $p=0.58$; IGF-1 (rs5742612), TT versus $\mathrm{CC}+\mathrm{CT}, p=0.59$, and $\mathrm{T}$ versus $\mathrm{C}, p=0.38$ ). In the subgroup of male patients $(n=19)$ no statistically significant associations were observed (AMPD1 (rs17602729), $\mathrm{CC}$ versus TT $+\mathrm{CT}, p=0.32$, and $\mathrm{C}$ versus $\mathrm{T}, p=0.12$; $V D R$ (rs2228670), $\mathrm{FF}$ versus $\mathrm{Ff}+\mathrm{ff}, p=0.45$, and $\mathrm{F}$ versus f, $p=0.35$; IGF-1 (rs5742612), TT versus CC + CT, $p=1$, and $\mathrm{T}$ versus $\mathrm{C}, p=0.68$ ). In conclusion, the genotypes and alleles of VDR, IGF-1, and AMPD1 polymorphisms could not be associated with gender.

Main thoracic curve was the most common curve type in male and female patients as well as surgical cases. In the subgroup of patients with thoracic $(n=62)$, lumbar $(n=12)$, and thoracolumbar $(n=31)$ scoliosis no association between the polymorphisms and the clinical phenotype was observed $(p>0.05)$. In conclusion, these genetic variants were not associated with the curve pattern.

Odds ratios of genotypes and alleles in the subgroups are summarised in Table 4.

The results of the statistical analysis in this study indicate that the VDR, IGF-1, and AMPD1 polymorphisms were not associated with susceptibility to IS, curve severity, curve pattern, onset of the disease, familial history, or gender. On the basis of these results the examined polymorphic variants could not be considered as genetic variants with predisposing or modifying effect in Bulgarian population. These results do not exclude a potential role of the same polymorphic markers in other population groups or impact of other polymorphisms of VDR, IGF-1, and AMPD1 on the etiology and pathogenesis of IS in Caucasian population.

\section{Conclusions}

In conclusion, this case-control study revealed no statistically significant association between the VDR, IGF-1, and AMPDI 
TABLE 4: Odds ratios of genotypes and alleles in different subgroups with IS.

\begin{tabular}{|c|c|c|c|}
\hline Subgroup & Gene & Genotype, allele & OR [95\% CI] \\
\hline \multirow{3}{*}{ General $(n=105)$} & $V D R$ & $\begin{array}{c}\text { FF versus } \mathrm{Ff}+\mathrm{ff} \\
\mathrm{F} \text { versus } \mathrm{f}\end{array}$ & $\begin{array}{l}1.08[0.68-1.73] \\
1.02[0.70-1.49]\end{array}$ \\
\hline & $I G F-1$ & $\begin{array}{c}\text { TT versus } \mathrm{CC}+\mathrm{CT} \\
\mathrm{T} \text { versus } \mathrm{C}\end{array}$ & $\begin{array}{l}1.15[0.54-2.45] \\
1.22[0.61-2.45]\end{array}$ \\
\hline & $A M P D 1$ & $\begin{array}{c}\mathrm{CC} \text { versus } \mathrm{TT}+\mathrm{CT} \\
\mathrm{C} \text { versus } \mathrm{T} \\
\end{array}$ & $\begin{array}{l}0.87[0.52-1.45] \\
0.83[0.53-1.29] \\
\end{array}$ \\
\hline \multirow{3}{*}{ AIS $(n=78)$} & $V D R$ & $\begin{array}{c}\text { FF versus } \mathrm{Ff}+\mathrm{ff} \\
\text { F versus } \mathrm{f}\end{array}$ & $\begin{array}{l}1.10[0.65-1.86] \\
1.02[0.67-1.55]\end{array}$ \\
\hline & $I G F-1$ & $\begin{array}{c}\text { TT versus } \mathrm{CC}+\mathrm{CT} \\
\mathrm{T} \text { versus } \mathrm{C}\end{array}$ & $\begin{array}{l}0.92[0.42-2.01] \\
0.98[0.48-2.01]\end{array}$ \\
\hline & $A M P D 1$ & $\begin{array}{c}\mathrm{CC} \text { versus } \mathrm{TT}+\mathrm{CT} \\
\mathrm{C} \text { versus } \mathrm{T} \\
\end{array}$ & $\begin{array}{l}0.86[0.49-1.51] \\
0.84[0.51-1.38] \\
\end{array}$ \\
\hline \multirow{3}{*}{ Familial history of IS $(n=28)$} & $V D R$ & $\begin{array}{c}\text { FF versus Ff + ff } \\
\text { F versus } \mathrm{f}\end{array}$ & $\begin{array}{l}1.46[0.65-3.27] \\
1.20[0.62-2.32]\end{array}$ \\
\hline & $I G F-1$ & $\begin{array}{c}\text { TT versus } \mathrm{CC}+\mathrm{CT} \\
\mathrm{T} \text { versus } \mathrm{C}\end{array}$ & $\begin{array}{l}1.76[0.39-7.85] \\
1.31[0.39-4.45]\end{array}$ \\
\hline & $A M P D 1$ & $\begin{array}{c}\mathrm{CC} \text { versus } \mathrm{TT}+\mathrm{CT} \\
\mathrm{C} \text { versus } \mathrm{T} \\
\end{array}$ & $\begin{array}{l}2.29[0.76-6.88] \\
2.29[0.80-6.57] \\
\end{array}$ \\
\hline \multirow{3}{*}{ Cobb angle $>40^{\circ}(n=84)$} & $V D R$ & $\begin{array}{c}\text { FF versus } \mathrm{Ff}+\mathrm{ff} \\
\text { F versus } \mathrm{f}\end{array}$ & $\begin{array}{l}0.94[0.57-1.57] \\
0.96[0.65-1.44]\end{array}$ \\
\hline & $I G F-1$ & $\begin{array}{c}\text { TT versus } \mathrm{CC}+\mathrm{CT} \\
\text { T versus } \mathrm{C}\end{array}$ & $\begin{array}{l}1.00[0.46-2.18] \\
1.17[0.56-2.46]\end{array}$ \\
\hline & $A M P D 1$ & $\begin{array}{c}\mathrm{CC} \text { versus } \mathrm{TT}+\mathrm{CT} \\
\mathrm{C} \text { versus } \mathrm{T} \\
\end{array}$ & $\begin{array}{l}0.76[0.44-1.32] \\
0.72[0.45-1.15] \\
\end{array}$ \\
\hline \multirow{3}{*}{ Thoracic scoliosis $(n=62)$} & $V D R$ & $\begin{array}{c}\text { FF versus Ff + ff } \\
\text { F versus } \mathrm{f}\end{array}$ & $\begin{array}{l}1.50[0.84-2.67] \\
1.25[0.78-2.00]\end{array}$ \\
\hline & $I G F-1$ & $\begin{array}{c}\text { TT versus } \mathrm{CC}+\mathrm{CT} \\
\text { T versus } \mathrm{C}\end{array}$ & $\begin{array}{l}1.06[0.44-2.59] \\
1.24[0.53-2.90]\end{array}$ \\
\hline & $A M P D 1$ & $\begin{array}{c}\text { CC versus TT + CT } \\
\text { C versus T }\end{array}$ & $\begin{array}{l}1.07[0.57-2.01] \\
1.03[0.59-1.79] \\
\end{array}$ \\
\hline \multirow{3}{*}{ Lumbar scoliosis $(n=12)$} & $V D R$ & $\begin{array}{c}\text { FF versus } \mathrm{Ff}+\mathrm{ff} \\
\text { F versus } \mathrm{f}\end{array}$ & $\begin{array}{l}1.32[0.41-4.30] \\
1.09[0.42-2.82]\end{array}$ \\
\hline & $I G F-1$ & $\begin{array}{c}\text { TT versus } \mathrm{CC}+\mathrm{CT} \\
\mathrm{T} \text { versus } \mathrm{C}\end{array}$ & $\begin{array}{c}1.48[0.31-7.15] \\
1.93[0.54-6.84]\end{array}$ \\
\hline & $A M P D 1$ & $\begin{array}{c}\text { CC versus } \mathrm{TT}+\mathrm{CT} \\
\mathrm{C} \text { versus } \mathrm{T} \\
\end{array}$ & $\begin{array}{c}1.91[0.41-8.97] \\
1.24[0.36-4.26] \\
\end{array}$ \\
\hline \multirow{3}{*}{ Thoracolumbar scoliosis $(n=31)$} & $V D R$ & $\begin{array}{c}\text { FF versus Ff + ff } \\
\text { F versus } \mathrm{f}\end{array}$ & $\begin{array}{l}1.93[0.88-4.22] \\
1.41[0.80-2.49]\end{array}$ \\
\hline & $I G F-1$ & $\begin{array}{c}\text { TT versus } \mathrm{CC}+\mathrm{CT} \\
\mathrm{T} \text { versus } \mathrm{C}\end{array}$ & $\begin{array}{l}1.96[0.44-8.72] \\
2.23[0.52-9.57]\end{array}$ \\
\hline & $A M P D 1$ & $\begin{array}{c}\mathrm{CC} \text { versus } \mathrm{TT}+\mathrm{CT} \\
\mathrm{C} \text { versus } \mathrm{T}\end{array}$ & $\begin{array}{l}1.66[0.76-3.62] \\
1.81[0.95-3.43] \\
\end{array}$ \\
\hline \multirow{3}{*}{ Males $(n=19)$} & $V D R$ & $\begin{array}{c}\text { FF versus } \mathrm{Ff}+\mathrm{ff} \\
\text { F versus } \mathrm{f}\end{array}$ & $\begin{array}{l}0.65[0.22-1.98] \\
0.65[0.27-1.60]\end{array}$ \\
\hline & $I G F-1$ & $\begin{array}{c}\text { TT versus } \mathrm{CC}+\mathrm{CT} \\
\mathrm{T} \text { versus } \mathrm{C}\end{array}$ & $\begin{array}{l}0.73[0.11-4.78] \\
0.65[0.14-3.05]\end{array}$ \\
\hline & AMPD1 & $\begin{array}{c}\mathrm{CC} \text { versus } \mathrm{TT}+\mathrm{CT} \\
\mathrm{C} \text { versus } \mathrm{T} \\
\end{array}$ & $\begin{array}{l}0.56[0.18-1.77] \\
0.47[0.18-1.24] \\
\end{array}$ \\
\hline \multirow{3}{*}{ Females $(n=86)$} & $V D R$ & $\begin{array}{c}\text { FF versus } F f+f f \\
F \text { versus } f\end{array}$ & $\begin{array}{c}1.21[0.72-2.03] \\
1.13[0.74-1.71]\end{array}$ \\
\hline & $I G F-1$ & $\begin{array}{c}\text { TT versus } \mathrm{CC}+\mathrm{CT} \\
\text { T versus } \mathrm{C}\end{array}$ & $\begin{array}{l}1.25[0.55-2.86] \\
1.42[0.65-3.11]\end{array}$ \\
\hline & $A M P D 1$ & $\begin{array}{c}\text { CC versus TT + CT } \\
\text { C versus T }\end{array}$ & $\begin{array}{l}0.97[0.54-1.73] \\
0.96[0.58-1.58]\end{array}$ \\
\hline
\end{tabular}

All $p$ values were not significant. IS indicates idiopathic scoliosis; AIS: adolescent idiopathic scoliosis; OR: odds ratio; CI: confidence interval; VDR: vitamin $D$ receptor; IGF-1: insulin-like growth factor-1; AMPDI: adenosine monophosphate deaminase 1. 
polymorphisms and the susceptibility to IS or curve severity in Bulgarian patients.

No genotype or allele of the VDR, IGF-1, and AMPD1 polymorphisms was found to be correlated with familial history, age, gender, or curve pattern.

Replication case-control studies will be needed to examine the association between these candidate-genes and IS in different populations.

The identification of molecular markers for IS could be useful for early detection and prognosis of the risk for a rapid progression of the curve. That would permit early stage treatment of the patient with the least invasive procedures.

\section{Disclosure}

This paper does not include any information about medical device(s) or drug(s). No benefits in any form have been or will be received from any commercial entity related directly or indirectly to the subject of this paper.

\section{Conflict of Interests}

The authors declare that there is no conflict of interests regarding the publication of this paper.

\section{Acknowledgments}

The authors would like to thank all participants for their support in this study. This work was supported by the Medical University-Sofia under Grant no. 49/2012 and Grant no. 5D/2014.

\section{References}

[1] C. S. Ku, P. K. E. Magnusson, K. S. Chia, and Y. Pawitan, "Research on rare variants for complex diseases," in $e L S$, John Wiley \& Sons, Chichester, UK, 2010.

[2] O. Zuk, E. Hechter, S. R. Sunyaev, and E. S. Lander, "The mystery of missing heritability: genetic interactions create phantom heritability," Proceedings of the National Academy of Sciences of the United States of America, vol. 109, no. 4, pp. 1193-1198, 2012.

[3] J. J. Asimit and E. Zeggini, "Testing for rare variant associations in complex diseases," Genome Medicine, vol. 3, no. 4, p. 24, 2011.

[4] G. Gibson, "Rare and common variants: twenty arguments," Nature Reviews Genetics, vol. 13, no. 2, pp. 135-145, 2012.

[5] J. De Ligt, J. A. Veltman, and L. E. Vissers, "Point mutations as a source of de novo genetic disease," Current Opinion in Genetics \& Development, vol. 23, no. 3, pp. 257-263, 2013.

[6] G. Saggese, G. I. Baroncelli, and S. Bertelloni, "Puberty and bone development," Best Practice \& Research: Clinical Endocrinology \& Metabolism, vol. 16, no. 1, pp. 53-64, 2002.

[7] N. A. Morrison, P. M. George, T. Vaughan, M. W. Tilyard, C. M. Frampton, and N. L. Gilchrist, "Vitamin D receptor genotypes influence the success of calcitriol therapy for recurrent vertebral fracture in osteoporosis," Pharmacogenetics and Genomics, vol. 15, no. 2, pp. 127-135, 2005.

[8] K. T. Suh, I.-S. Eun, and J. S. Lee, "Polymorphism in vitamin D receptor is associated with bone mineral density in patients with adolescent idiopathic scoliosis," European Spine Journal, vol. 19, no. 9, pp. 1545-1550, 2010.
[9] H. Yilmaz, C. Zateri, A. Uludag, C. Bakar, S. Kosar, and O. Ozdemir, "Single-nucleotide polymorphism in Turkish patients with adolescent idiopathic scoliosis: curve progression is not related with MATN-1, LCT C/T-13910, and VDR BsmI," Journal of Orthopaedic Research, vol. 30, no. 9, pp. 1459-1463, 2012.

[10] A. G. Uitterlinden, Y. Fang, J. B. J. van Meurs, H. A. P. Pols, and J. P. T. M. van Leeuwen, "Genetics and biology of vitamin D receptor polymorphisms," Gene, vol. 338, no. 2, pp. 143-156, 2004.

[11] Y. Fang, J. B. J. van Meurs, A. P. Bergink et al., "Cdx-2 polymorphism in the promoter region of the human vitamin $\mathrm{D}$ receptor gene determines susceptibility to fracture in the elderly," Journal of Bone and Mineral Research, vol. 18, no. 9, pp. 1632-1641, 2003.

[12] H. Arai, K.-I. Miyamoto, Y. Taketani et al., "A vitamin D receptor gene polymorphism in the translation initiation codon: effect on protein activity and relation to bone mineral density in Japanese women," Journal of Bone and Mineral Research, vol. 12, no. 6, pp. 915-921, 1997.

[13] P. W. Jurutka, L. S. Remus, G. K. Whitfield et al., "The polymorphic $\mathrm{N}$ terminus in human vitamin $\mathrm{D}$ receptor isoforms influences transcriptional activity by modulating interaction with transcription factor IIB," Molecular Endocrinology, vol. 14, no. 3, pp. 401-420, 2000.

[14] H. Y. Yeung, N. L. Tang, K. M. Lee et al., "Genetic association study of insulin-like growth factor-I (IGF-I) gene with curve severity and osteopenia in adolescent idiopathic scoliosis," Studies in Health Technology and Informatics, vol. 123, pp. 1824, 2006.

[15] Y. Yang, Z. Wu, T. Zhao et al., "Adolescent idiopathic scoliosis and the single-nucleotide polymorphism of the growth hormone receptor and IGF-1 genes," Orthopedics, vol. 32, no. 6, p. 411, 2009.

[16] Y. Takahashi, M. Matsumoto, T. Karasugi et al., "Lack of association between adolescent idiopathic scoliosis and previously reported single nucleotide polymorphisms in MATN1, MTNR1B, TPH1, and IGF1 in a Japanese population," Journal of Orthopaedic Research, vol. 29, no. 7, pp. 1055-1058, 2011.

[17] E. S. Moon, H. S. Kim, V. Sharma et al., "Analysis of single nucleotide polymorphism in adolescent idiopathic scoliosis in Korea: for personalized treatment," Yonsei Medical Journal, vol. 54, no. 2, pp. 500-509, 2013.

[18] P. Cieszczyk, M. Ostanek, A. Leońska-Duniec et al., "Distribution of the AMPD1 C34T polymorphism in Polish poweroriented athletes," Journal of Sports Sciences, vol. 30, no. 1, pp. 31-35, 2012.

[19] V. Ginevičiene, A. Jakaitiene, A. Pranculis, K. Milašius, L. Tubelis, and A. Utkus, "AMPD1 rs17602729 is associated with physical performance of sprint and power in elite Lithuanian athletes," BMC Genetics, vol. 15, article 58, 2014.

[20] J. C. Y. Cheng, N. L. S. Tang, H.-Y. Yeung, and N. Miller, "Genetic association of complex traits: using idiopathic scoliosis as an example," Clinical Orthopaedics and Related Research, vol. 462, pp. 38-44, 2007.

[21] F. Altaf, "Adolescent idiopathic scoliosis," British Medical Journal, vol. 346, Article ID f2508, 2013. 

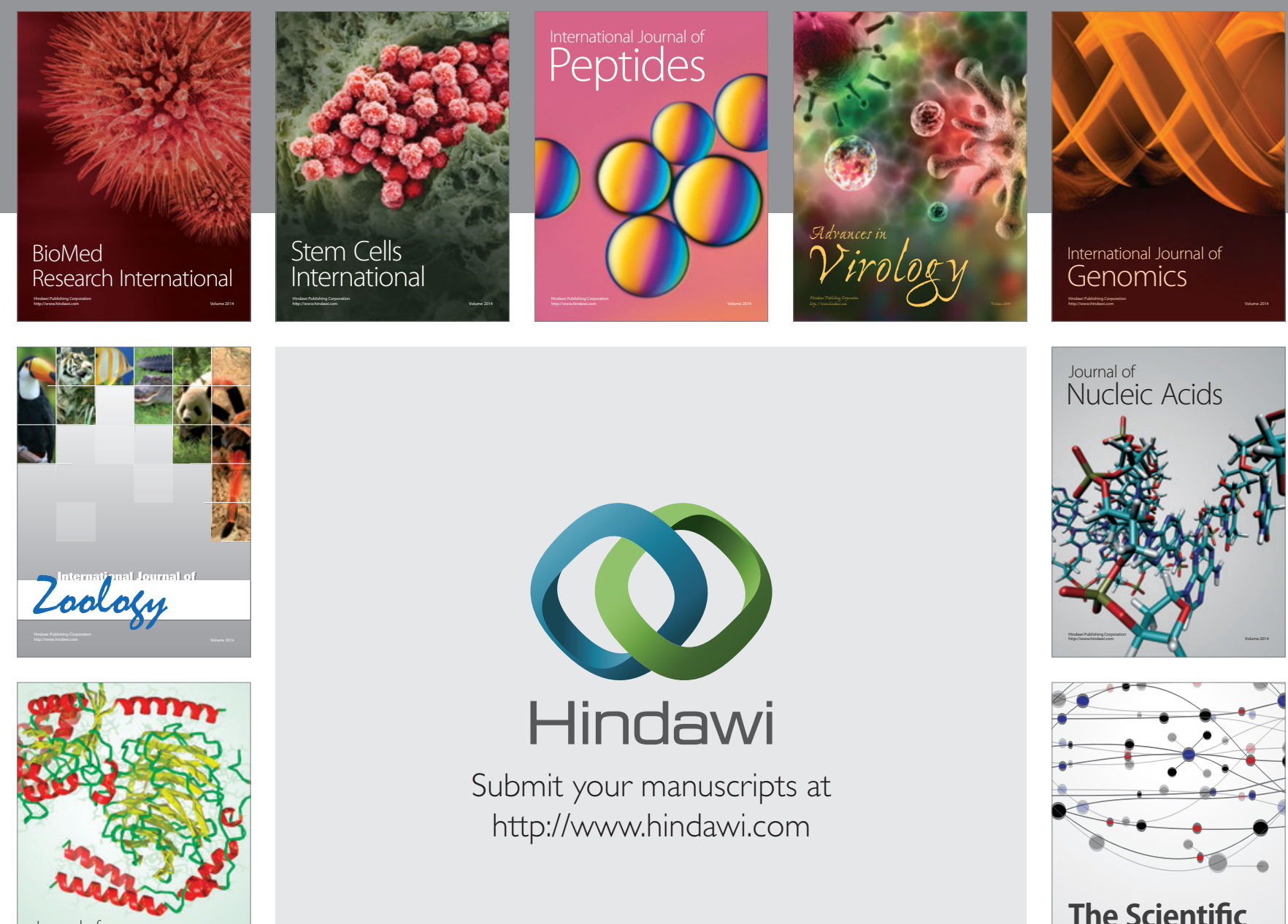

Submit your manuscripts at

http://www.hindawi.com

Journal of
Signal Transduction
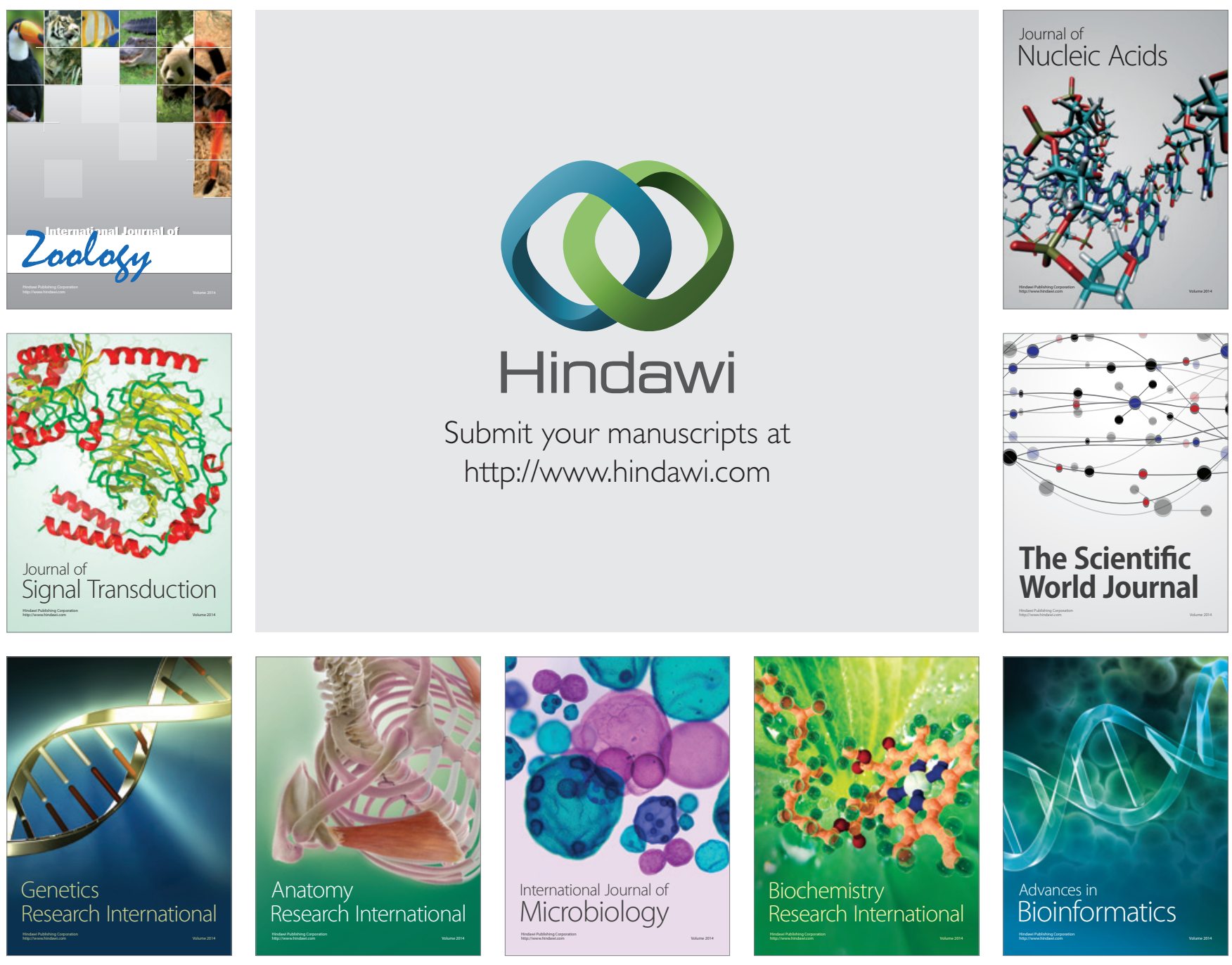

The Scientific World Journal
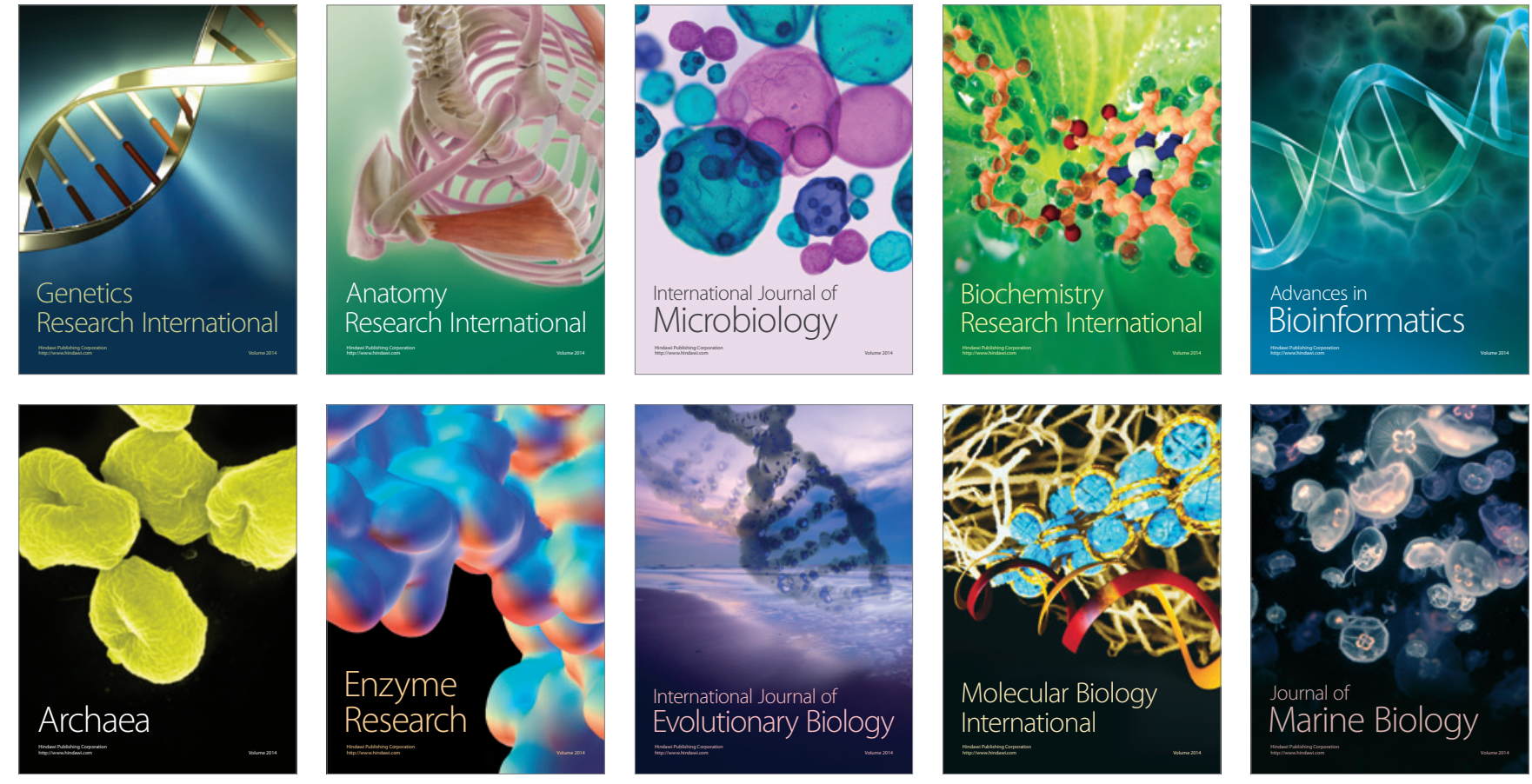